ORIGINAL ARTICLE

\title{
INCRETIN HORMONES, THYROID STIMULATING HORMONE AND HUMAN GROWTH HORMONE RESPONSES DURING OGTT IN NEWLY DIAGNOSED T2DM PATIENTS
}

\author{
KA Jhuma ${ }^{1}$, ASM Giasuddin², MS Hossain ${ }^{3}$, AMM Haq ${ }^{4}$ \\ ${ }^{1}$ Dept of Biochemistry, Medical College for Women and Hospital, Dhaka; ${ }^{2}$ Medical Research Unit, Medical \\ and Health Welfare Trust, Dhaka; ${ }^{3}$ Dept of Biochemistry and Molecular Biology, Jahangirnagar University, \\ Savar, Dhaka; ${ }^{4}$ Dept of Medicine, Medical College for Women and Hospital, Dhaka
}

\begin{abstract}
Several research groups have reported variable results about incretin effects of glucose-dependent insulinotropic polypeptide (GIP) and glucagon-like peptide-1(GLP-1), altered thyroid stimulating hormone (TSH) status, human growth hormone (hGH) deficiency and perturbed cytokines balances in type 2 diabetes mellitus (T2DM). The present case-control prospective interventional study was conducted investigating responses of incretin hormones (GIP, GLP-1), TSH and hGH to oral glucose tolerance test (OGTT) in newly diagnosed Bangladeshi T2DM patient. Blood samples were collected from 36 OGTT positive newly diagnosed T2DM patients as cases and 30 normal adults as controls at ' 0 ' minute (fasting) and at 2 hours after OGTT. Laboratory investigations were done and special parameters in serum, i.e. hGH, TSH, Insulin, GIP and GLP-1 were analyzed using enzyme immunoassay (EIA) kits. Statistical analyses were made by Student's ' $t$ ' test using SPSS programm. T2DM patients (cases) had FBG and BG2Hr levels much higher than controls $(\mathrm{p}<0.001)$. No significant differences were observed between controls and cases for F-TSH $(p=0.927)$, TSH2HrA $(p=0.413)$, F-hGH $(p=0.532)$ and hGH2HrA $(p=0.773)$ levels. It was observed that F-GIP $(p=0.309)$ and F-GLP-1 $(p=0.984)$ levels were similar between cases and controls. Interestingly, control subjects responded to OGTT by increasing GIP2HA and GLP-1, 2HR levels about 3 times compared to F-GIP and F-GLP-1 ( $<<0.001)$. In cases, F-GIP and F-GLP-1 levels were also raised responding to OGTT but by about 1.5 times only compared to F-GIP and F-GLP-1 $(p<0.025)$. Although no significant differences were observed for F-TSH, TSH2HrA, F-hGH and hGH2HrA between cases and controls, F-GIP and F-GLP-1 levels were raised responding to OGTT in cases by about 1.5 times only compared to about 3.0 times in controls subjects. But responses of GIP and GLP-1 to glucose load were lower leading to reduced insulin levels in these T2DM patients reported earlier. Further studies with a larger sample size including cytokines are warranted.
\end{abstract}

Key Words: Diabetes Mellitus. T2DM, GIP, GLP-1, TSH, hGH

\section{Introduction}

Diabetes mellitus (DM) poses a major global health threat, both in the developed and developing countries. It is a serious global health issue with type 2 diabetes mellitus (T2DM) accounting for about $90-95 \%$ of all cases. It is estimated that about $7.8 \%$ of the world's population aged between 20 and 79 years will have T2DM by $2030^{1-3}$.

Bangladesh J Med Biochem 2018; 11(1): 09-16
Although glucose-tolerant individuals are capable of adjusting their insulin secretion to their actual insulin sensitivity, people with T2DM are incapable of doing so. Beta-cell failure is the hallmark of this disease, although failure may be precipitated by the development of insulin resistance. In healthy subjects, a considerable part of the postprandial insulin response is due to 
KA Jhuma, ASM Giasuddin, MS Hossain et al

the actions of the incretin hormones, i.e. glucagon-like peptide-1 (GLP-1) and glucosedependent insulinotropic polypeptide (GIP) particularly. Together, these two hormones are mainly responsible for the so-called incretin effect $^{3}$. A convenient way of describing the effect is to calculate the gastro-intestinally mediated glucose disposal (GIGD) ${ }^{3,4}$.

The normal human body has a remarkable capacity to handle the intake of increasing amounts of glucose and is therefore capable of maintaining almost unchanged postprandial glucose excursions, regardless of the oral load. In people with T2DM, this ability is dramatically reduced as illustrated by calculation of the GIGD. The almost complete loss of GIGD is typically accompanied by a greatly reduced difference between the insulin responses to the oral and the intravenous glucose load, i.e. the incretin effect ${ }^{5,6}$. The loss of incretin effect is therefore likely to contribute importantly to the postprandial hyperglycemia in T2DM. Research carried out by several groups during the last decades has indicated that the incretin effect is mediated mainly by GIP and GLP-1 and no other gut hormones fulfill all criteria to act as incretin hormones $^{7-10}$.

The concentrations of GIP have been reported to be elevated, decreased and unchanged in patients with T2DM. Toft-Nielsen et al. found slightly decreased postprandial GIP concentrations in a large group of T2DM patients compared with a matched control group of non-diabetic subjects ${ }^{11}$. A major secretory defect regarding GIP secretion did not seem to exist in T2DM. Toft-Nielsen et al. also found a pronounced impairment of the postprandial GLP-1 response, particularly during the later postprandial phase (after the first 60 min) ${ }^{11,12}$. Some other studies could not confirm decreased GLP-1 responses in T2DM patients and reported contradictory results ${ }^{13,14}$.

DM and thyroid disorders are endocrine abnormalities that are interrelated to each other, subclinical hypothyroidism being the most common disorder in T2DM. Thyroid hormones are necessary for normal glucose metabolism. Hyper or hypo secretion of thyroid hormones and thyroid stimulating hormone (TSH) can alter glucose homeostasis. Thyroid disorders not only worsen the metabolic control but also affect the management of diabetes. Therefore, DM patients need to be screened for thyroid dysfunction. American Diabetic Association (ADA) has proposed that the people with DM to be checked for thyroid disorders ${ }^{15-19}$. The magnitude of health problems related to DM in Bangladesh has been increasing rapidly, although limited study on hypothyroidism among T2DM has been reported from Bangladesh ${ }^{20}$.

In addition, human growth hormone (hGH) deficiency may result in an increased risk of developing T2DM along with other clinical symptoms and abnormalities as reported in some studies. The insulin and hGH/insulin-like growth factor-1 (IGF-1) axis are two endocrine systems that are interlinked at many levels. hGH is one of the glucose counter-regulatory hormones, rising in response to hypoglycemia which has both intrinsic hyperglycemic actions and causes insulin resistance. Growth is compromised in poorly controlled diabetic children; however, a causal link with altered hGH/IGF-1 levels has not been proven. In poorly controlled diabetics, hGH levels are invariably raised whilst normal or low levels of IGF-1 indicating dissociation between the two factors. Raised hGH levels could result from altered hypothalamic/pituitary control or reduced feedback inhibition. That $\mathrm{hGH}$ has an effect on glycemic control is most evident from the abnormal glucose tolerance seen in acromegalics. Altered hGH/IGF-1 levels have been implicated in the long-term complications associated with diabetes ${ }^{21-23}$.

Literature survey has indicated that no studies were done or reported on incretin hormones, TSH 
Incretin Hormones, Thyroid Stimulating Hormone and Human

status and hGH level and their responses to glucose load in newly diagnosed Bangladeshi patients with T2DM. Thus, we investigated serum incretin hormones (GIP, GLP-1), TSH and hGH and insulin status and their responses to oral glucose load (OGTT) in Bangladeshi T2DM patients and healthy control subjects in the present case-control prospective interventional study. The results on incretin hormones and insulin responses in these patients have been published recently ${ }^{24}$. In the present article, we have therefore reported the results of our study on the incretin hormones (GIP, GLP-1), TSH status and hGH level and their responses to OGTT in our newly diagnosed Bangladeshi T2DM patients comparing with normal control subjects.

\section{Materials and Methods}

The methodologies of this case-control prospective interventional study were reported in our recently published article ${ }^{24}$. This study was conducted during the period from November 2013 to June 2014 at the Medical Research Unit (MRU), Medical and Health Welfare Trust (MHWT), Uttara, Dhaka, Bangladesh with a research grant obtained from the Ministry of Science and Technology (MOST), Dhaka, Bangladesh. Suspected patients with T2DM had undergone oral glucose tolerance test (OGTT) after fasting. Blood samples were collected from individual patients at 'O' min (Fasting) and at 2Hrs (120 min) after glucose load. Samples were aliquoted for routine analyses and special research investigations. Among the routine analysis, glucose levels (Fasting/FBG, 2HA) and other usual routine tests in blood, serum and urine were done. Serum aliquots were preserved for a short time at $-20^{\circ} \mathrm{C}$ to $-30^{\circ} \mathrm{C}$ for incretin hormones (GIP, GLP-1), TSH, $\mathrm{hGH}$ and other special investigations. A total of 36 OGTT positive adult patients (male: 15, female: 21 ), only newly diagnosed T2DM patients (cases) were included in this study. Those who had other diseases such as thyroid diseases, any endocrine disorders, renal diseases, hypertension were excluded. And 30 normal healthy adults (male: 12, female: 18) were also investigated in parallel as normal control subjects. Routine laboratory investigations such as blood glucose, $\mathrm{CBC}, \mathrm{HbA} 1 \mathrm{c}$, LFTs, TFTs, RFTs were made according to usual clinical laboratory methods as practiced in the hospital laboratory. The special investigations, i.e. serum insulin, TSH, hGH, GIP and GLP-I, were made by adopting enzyme immunoassay (EIA) methods using kits obtained from reputed commercial companies such as R\&D Systems (USA), Calbiotech (USA), Novatech (Germany). Statistical analyses were performed by Student's ' $t$ ' test using SPSS programm.

\section{Results}

The results of the special laboratory investigations i.e. glucose (Fasting/FBG, 2HA), TSH, hGH, GIP, GLP-1 in normal controls and T2DM cases are stated in Table-I, Table-II, Table-III, Table-IV and Table -V respectively. T2DM patients (cases) had FBG and 2HA levels much higher than controls $(\mathrm{p}<0.001)$ (TableI). No significant differences were observed between cases and controls for F-TSH $(p=0.927), \quad$ TSH $2 H A \quad(p=0.413), \quad$ F-hGH $(p=0.532)$ and hGH2HA $(p=0.773)$ levels (Table-II, Table-III). It was observed that F-GIP $(p=0.309)$ and F-GLP-1 $(p=0.984)$ levels were similar between cases and controls (Table-IV, Table V). Interestingly, control subjects responded to OGTT by increasing GIP2Hr and GLP-1, 2Hr levels about 3 times compared to FGIP and F-GLP-1 $(\mathrm{p}<0.001)$ and in cases, FGIP and F-GLP-1 levels were also raised responding to OGTT but by about 1.5 times only $(\mathrm{p}<0.001)$ (Table-IV, Table-V). In these T2DM patients (cases), F-Insulin $(\mathrm{p}<0.001)$ and Insulin $2 \mathrm{Hr}(\mathrm{p}<0.001)$ were much lower than controls, although Insulin $2 \mathrm{Hr}$ level was higher than F-Insulin level in cases $(p<0.001)$ which we reported previously 24 . 
Table-I: FBG and 2HABG levels in normal controls and T2DM cases

\begin{tabular}{|c|c|c|c|c|}
\hline \multirow[b]{2}{*}{ Parameter } & \multicolumn{2}{|c|}{ Glucose (mmol/L) } & \multicolumn{2}{|c|}{ Glucose $(\mathrm{mmol} / \mathrm{L})$} \\
\hline & $\begin{array}{c}\text { FBG } \\
\text { (control) }\end{array}$ & $\begin{array}{l}\text { FBG } \\
\text { (cases) }\end{array}$ & $\begin{array}{l}\text { BG 2Hr } \\
\text { (controls) }\end{array}$ & $\begin{array}{l}\text { BG } 2 \mathrm{Hr} \\
\text { (cases) }\end{array}$ \\
\hline Number & $\begin{array}{c}30 \\
(12 \mathrm{M}, 18 \mathrm{~F})\end{array}$ & $\begin{array}{c}36 \\
(15 \mathrm{M}, 21 \mathrm{~F})\end{array}$ & $\begin{array}{c}30 \\
(12 \mathrm{M}, 18 \mathrm{~F})\end{array}$ & $\begin{array}{c}36 \\
(15 \mathrm{M}, 21 \mathrm{~F})\end{array}$ \\
\hline Observed range & $4.0-6.50$ & $6.31-14.21$ & $5.50-7.80$ & $8.52-23.21$ \\
\hline Mean \pm SD & $5.19 \pm 0.71$ & $10.09 \pm 1.94$ & $6.47 \pm 0.66$ & $14.56 \pm 4.77$ \\
\hline $\begin{array}{l}\text { Student's 't'-test } \\
\text { (control vs cases) }\end{array}$ & \multicolumn{2}{|c|}{$\mathrm{p}<0.001 * *$} & \multicolumn{2}{|c|}{$\mathrm{p}<0.001 * *$} \\
\hline Paired 't'-test & \multicolumn{4}{|c|}{$\begin{array}{l}\text { controls (FBG vs BG } 2 \mathrm{Hr} \text { ): } \mathrm{P}<0.025^{* *} \\
\text { cases (FBG vs BG2Hr): } \mathrm{P}<0.005^{* *}\end{array}$} \\
\hline
\end{tabular}

M: Male, F: Female; FBG: Fasting blood glucose, BG 2Hr: Blood glucose at 2hrs of OGTT.

$* * P \leqslant 0.05$ : Significant, $P>0.05$ : Not Significant.

Table-II: F-TSH and TSH 2Hr levels in controls and T2DM cases

\begin{tabular}{|c|c|c|c|c|}
\hline \multirow{2}{*}{ Parameter } & \multicolumn{2}{|c|}{$\mathrm{TSH}(\mu \mathrm{U} / \mathrm{ml})$} & \multicolumn{2}{|c|}{$\mathrm{TSH}(\mu \mathrm{U} / \mathrm{ml})$} \\
\hline & $\begin{array}{l}\text { F-TSH } \\
\text { (control) }\end{array}$ & $\begin{array}{l}\text { F-TSH } \\
\text { (cases) }\end{array}$ & $\begin{array}{l}\mathrm{TSH} 2 \mathrm{Hr} \\
\text { (control) }\end{array}$ & $\begin{array}{c}\text { TSH2Hr } \\
\text { (cases) }\end{array}$ \\
\hline Number & $\begin{array}{c}30 \\
(12 \mathrm{M}, 18 \mathrm{~F})\end{array}$ & $\begin{array}{c}36 \\
(15 \mathrm{M}, 21 \mathrm{~F})\end{array}$ & $\begin{array}{c}30 \\
(12 \mathrm{M}, 18 \mathrm{~F})\end{array}$ & $\begin{array}{c}36 \\
(15 \mathrm{M}, 21 \mathrm{~F})\end{array}$ \\
\hline Observed range & $0.30-11.10$ & $0.42-13.72$ & $0.40-13.70$ & $3.32-11.12$ \\
\hline Mean \pm SD & $3.29 \pm 2.59$ & $3.35 \pm 2.72$ & $3.55 \pm 2.88$ & $3.01 \pm 2.46$ \\
\hline $\begin{array}{l}\text { Student's 't'-test } \\
\text { (control vs cases) }\end{array}$ & \multicolumn{2}{|c|}{$\mathrm{p}=0.927$} & \multicolumn{2}{|c|}{$\mathrm{p}=0.413$} \\
\hline Paired ' $t$ '-test & \multicolumn{4}{|c|}{$\begin{array}{l}\text { controls (F-TSH vs TSH2Hr): } \mathrm{P}<0.045^{* *} \\
\text { cases (F-TSH vs TSH2Hr): } \mathrm{P}<0.011^{* *}\end{array}$} \\
\hline
\end{tabular}

M: Male, F: Female; F-TSH: Fasting thyroid stimulating hormone; TSH2Hr: Thyroid Stimulating hormone at 2 hrs of OGTT. ${ }^{*} * P \leqslant 0.05$ : Significant, $P>0.05$ : Not Significant.
Table-III: F-hGH and hGH2Hr levels in controls and T2DM cases

\begin{tabular}{lcccc}
\hline \multirow{2}{*}{ Parameter } & \multicolumn{2}{c}{ hGH (mmol/L) } & \multicolumn{2}{c}{ hGH (mmol/L) } \\
\cline { 2 - 5 } & $\begin{array}{c}\text { F-hGH } \\
\text { (control) }\end{array}$ & $\begin{array}{c}\text { F-hGH } \\
\text { (cases) }\end{array}$ & $\begin{array}{c}\text { hGH2Hr } \\
\text { (control) }\end{array}$ & $\begin{array}{c}\text { hGH2Hr } \\
\text { (cases) }\end{array}$ \\
\hline Number & $\begin{array}{c}30 \\
(12 \mathrm{M}, 18 \mathrm{~F})\end{array}$ & $\begin{array}{c}36 \\
(15 \mathrm{M}, 21 \mathrm{~F})\end{array}$ & $\begin{array}{c}30 \\
(12 \mathrm{M}, 18 \mathrm{~F})\end{array}$ & $\begin{array}{c}36 \\
(15 \mathrm{M}, 21 \mathrm{~F})\end{array}$ \\
Observed range & $0.50-5.0$ & $0.11-5.32$ & $0.60-5.30$ & $0.12-5.21$ \\
Mean \pm SD & $1.26 \pm 0.96$ & $1.11 \pm 1.01$ & $1.24 \pm 1.04$ & $1.17 \pm 0.94$ \\
Student's 't'-test & & $\mathrm{p}=0.0532$ & $\mathrm{p}=0.773$ \\
(control vs cases) & & & & \\
Paired 't'-test & \multicolumn{2}{c}{$\begin{array}{c}\text { control (F-hGH vs hGH 2Hr): P<0.777** } \\
\text { cases (F-hGH vs hGH 2Hr): P=0.349** }\end{array}$} \\
\hline
\end{tabular}

M: Male, F: Female; F-hGH: Fasting human growth hormone; hGH 2Hr: Human growth hormone at $2 \mathrm{Hrs}$ of OGTT. ${ }^{*} P \leqslant 0.05$ : significant, $P>0.05$ : Not significant.

Table-IV: F-GIP and GIP2Hr levels in normal controls and T2DM cases Parameter GIP (pg/ml) GIP (pg/ml)

\begin{tabular}{lcccc}
\hline \multirow{2}{*}{ Parameter } & \multicolumn{2}{c}{ GIP (pg/ml) } & \multicolumn{2}{c}{ GIP (pg/ml) } \\
\cline { 2 - 5 } & $\begin{array}{c}\text { FGIP } \\
\text { (control) }\end{array}$ & $\begin{array}{c}\text { F-GIP } \\
\text { (cases) }\end{array}$ & $\begin{array}{c}\text { GIP2Hr } \\
\text { (control) }\end{array}$ & $\begin{array}{c}\text { HGH2Hr } \\
\text { (case) }\end{array}$ \\
\hline Number & 30 & 36 & 30 & 36 \\
& $(12 \mathrm{M}, 18 \mathrm{~F})$ & $(15 \mathrm{M}, 21 \mathrm{~F})$ & $(12 \mathrm{M}, 18 \mathrm{~F})$ & $(15 \mathrm{M}, 21 \mathrm{~F})$ \\
Observed range & $42.0-85.40$ & $42.11-81.12$ & $105.1-213.5$ & $84.21-162.21$ \\
Mean \pm SD & $63.42 \pm 13.80$ & $60.14 \pm 12.18$ & $158.56 \pm 34.49$ & $119.33 \pm 22.9$ \\
$\begin{array}{l}\text { Student's 't'-test } \\
\text { (control vs cases) }\end{array}$ & \multicolumn{2}{c}{$\mathrm{p}<0.309 * *$} & $\mathrm{p}<0.001 * *$ \\
Paired 't'-test & Controls (F-GIP vs GIP 2Hr): P<0.001** \\
& \multicolumn{2}{c}{ Cases (F-GIP vs GIP 2Hr): P<0.025** } \\
\hline
\end{tabular}

M: Male, F: Female; F-GIP: Fasting glucose-dependent insulinotropic polypeptide; GIP2Hr: Glucose-dependent insulinotropic polypeptide at $2 \mathrm{hrs}$ of OGTT. ${ }^{* * P} \leqslant 0.05$ : Significant, P>0.05: Not Significant 
Incretin Hormones, Thyroid Stimulating Hormone and Human

Table-V: F-GLP-1 and GLP-1, 2Hr levels in normal controls (NC) and T2DM patients (Pt)

\begin{tabular}{lcccc}
\hline Parameter & \multicolumn{2}{c}{ GLP-1 (pg/ml) } & \multicolumn{2}{c}{ GLP-1 (pg/ml) } \\
\cline { 2 - 5 } & $\begin{array}{c}\text { F-GLP-1 } \\
\text { (control) }\end{array}$ & $\begin{array}{c}\text { F-GLP-1 } \\
\text { (case) }\end{array}$ & $\begin{array}{c}\text { F-GLP-1 } \\
\text { (control) }\end{array}$ & $\begin{array}{c}\text { GLP-1 2Hr } \\
\text { (case) }\end{array}$ \\
\hline Number & 30 & 36 & 30 & 36 \\
& $(12 \mathrm{M}, 18 \mathrm{~F})$ & $(15 \mathrm{M}, 21 \mathrm{~F})$ & $(12 \mathrm{M}, 18 \mathrm{~F})$ & $(15 \mathrm{M}, 21 \mathrm{~F})$
\end{tabular}

$\begin{array}{lllll}\text { Observed range } & 32.40-75.10 & 33.22-78.12 & 97.20-225.30 & 42.51-111.02\end{array}$

Mean \pm SD $\quad 60.82 \pm 13.42 \quad 52.75 \pm 13.98 \quad 164.46 \pm 40.26 \quad 81.65 \pm 20.47$

Student's 't'-test

(control vs cases)

Paired 't'-test

control (F-GLP-1 vs GLP-1, 2Hr): $\mathrm{P}<0.001 * *$ case (F-GLP-1 vs GLP-1, 2Hr): $\mathrm{P}<0.025^{* *}$

M: Male, F: Female; F-GLP-1: Fasting glucagon-like peptide 1; GLP-1,2Hr: Glucagon-like peptide 1 at $2 \mathrm{Hrs}$ of OGTT. ${ }^{* * P} \leqslant 0.05$ : Significant, $P>0.05$ : Not Significant

\section{Discussion}

Our T2DM patients (cases) had FBG $(\mathrm{p}<0.001)$ and BG2Hr $(\mathrm{p}<0.001)$ levels much higher than control subjects $(\mathrm{p}<0.001)$ which were expected (Table-I). No significant differences were observed between cases and controls for F-TSH $(p=0.927)$, TSH $2 \mathrm{Hr}(\mathrm{p}=0.413), \mathrm{F}-\mathrm{hGH}(\mathrm{p}=0.532)$ and $\mathrm{hGH}$ $2 \mathrm{Hr}(\mathrm{p}=0.773)$ levels (Table-II, Table-III). It was observed that F-GIP $(\mathrm{p}=0.309)$ and F-GLP-1 $(p=0.984)$ levels were similar between cases and controls. Interestingly, control subjects responded to OGTT by increasing GIP 2Hr and GLP-1 $2 \mathrm{Hr}$ levels about 3 times compared to F-GIP and FGLP-1 $(\mathrm{p}<0.001)($ Table-IV, Table-V). In cases, F-GIP and F-GLP-1 levels were also raised responding to OGTT but by about 1.5 times $(\mathrm{p}<0.001)$. We reported previously that in these T2DM patients (case), F-Insulin $(p<0.001)$ and insulin 2HA $(p<0.001)$ were much lower than control subjects, although insulin $2 \mathrm{HrA}$ level was higher than F-Insulin level in cases $(p<0.001)$ which were reported previously 24 .

Most of the GIGD in healthy subjects is accounted for by the actions of the incretin hormones, but inhibition of hepatic glucose production by suppression of glucagon secretion, hepatic uptake of glucose from the portal vein and gut vein or liver vein reflex activity may also play a role. There is no doubt that the incretin hormones play a major role in GIGD in healthy subjects and it can be concluded that the incretin effect plays a major role for normal glucose tolerance. In people with T2DM, this ability is dramatically reduced as shown in our results similar to some other reports. The loss of incretin effect is therefore likely to contribute importantly to the postprandial hyperglycemia in T2DM ${ }^{5}$.

The concentrations of GIP have been reported to be elevated, decreased and unchanged in patients with T2DM. Toft-Nielsen et al. found slightly decreased postprandial GIP concentrations in a large group of T2DM patients compared with a matched control group of non-diabetic subjects ${ }^{11}$. A major secretory defect regarding GIP secretion did not seem to exist in T2DM. When GLP-1 was identified as the other important incretin hormone, it was relevant to evaluate GLP-1 secretion in T2DM also. ToftNielsen et al. found a pronounced impairment of the postprandial GLP-1 response in T2DM subjects, particularly during the later postprandial phase (after the first $60 \mathrm{~min})^{11,12}$. Some other studies could not confirm decreased GLP-1 responses in T2DM patients ${ }^{13,14}$. However, presence of some other unidentified incretin hormones yet to be discovered cannot be ruled out.

Holst et al. concluded that the dramatic loss in patients with T2DM of the ability to dispose of orally ingested glucose i.e. GIGD is related to the inability of the incretin hormones to increase insulin secretion after meal or glucose load ${ }^{25}$. Several lines of evidence support that the loss of incretin effect is secondary to development of diabetes ${ }^{25,26}$. However, more recent findings suggest that the loss of incretin effects in T2DM 
patients can only be explained by a specific loss of insulinotropic activity of the incretin hormones at physiological level $25,27,28$. In overt T2DM, the consequence of the impaired incretin effect is that the ability of the patients to efficiently dispose of orally as opposed to intravenously administered glucose is almost completely lost ${ }^{25}$.

Subclinical hypothyroidism is a common disorder in T2DM. Thyroid hormones are necessary for normal glucose metabolism. Hyper or hypo secretion of thyroid hormones can alter glucose homeostasis. Thyroid disorders not only worsen the metabolic control but also affect the management of diabetes. Therefore, DM patients need to be screened for thyroid dysfunction. ADA has proposed that the people with DM to be checked for thyroid disorders ${ }^{15-19}$. Although the magnitude of health problems related to DM in Bangladesh has been increasing rapidly, limited studies on hypothyroidism among T2DM have been reported from Bangladesh ${ }^{20}$.

Altered hGH/IGF-1 levels have been implicated in the long-term complications associated with diabetes. That hGH has an effect on glycemic control is most evident from the abnormal glucose tolerance seen in acromegalics. Raised hGH levels could result from altered hypothalamic/pituitary control or reduced feedback inhibition. In poorly controlled diabetics, hGH levels are invariably raised whilst normal or low levels of IGF-1 are found, indicating dissociation between the two factors $^{21-23}$.

We found that TSH and hGH levels were similar in controls and cases at fasting $(p=0.927$, $\mathrm{P}=0.532$ ). However, TSH response to OGTT in patients was significantly lower $(p=0.011)$, while hGH response was not significant $(\mathrm{p}=0.349)$. In controls, TSH response at $2 \mathrm{hrs}$ was higher $(p=0.047)$ while hGH response was not significant $(p=0.777)$. The reason for normal TSH and hGH levels may be due to the fact that our patient group was small in number and were newly diagnosed T2DM with short duration. But responses of GIP and GLP-1 to glucose load were decreased leading to reduced insulin levels in these T2DM patients reported earlier $^{24}$.

Our observations of relatively reduced capacity of T2DM patients to produce GIP and GLP-1 seemed to be relevant and interesting. These incretin hormones responses may be linked to pro-inflammatory and anti-inflammatory cytokines status. These cytokines are thought to impair insulin signaling and abnormally high levels of them are associated with insulin resistance and $\mathrm{T}_{2} \mathrm{DM}^{28-32}$. Also, it has been reported that anti-inflammatory cytokines counteract the cytotoxic effects of proinflammatory cytokines in insulin-producing cells $29,30,32$. It is therefore evident that perturbation of this delicate balance in favor of pro-inflammatory cytokines is a strong possibility as the pathogenetic mechanism towards development of T2DM. Further studies with a larger sample size including cytokines are required to confirm and extend our findings.

\section{Acknowledgements}

The authors appreciate Mr. TK Datta, Medical Technologist, Medical Research Unit (MRU), The Medical and Health Welfare Trust (MHWT) for technical assistance and Mr. SM Nawjes Ali, Laboratory Technologist-cumComputer Operator, MRU, MHWT, Uttara, Dhaka-1230, Bangladesh for computer composing the manuscript. The authors gratefully acknowledge the Ministry of Science \& Technology (MOST), Government of the People's Republic of Bangladesh, Dhaka for the generous financial support for the project through a research grant. 
Incretin Hormones, Thyroid Stimulating Hormone and Human

\section{References}

1. Rodbard HW, Blonde L, Braithwaite SS. American Association of Clinical Endocrinologists medical guide lines for clinical practice for the management of diabetes mellitus. Endocr Pract 2007; 13(Suppl 1): 1-68.

2. International Diabetes Federation: Diabetes Atlas. Brussels. IDF, 2010.

3. Holst JJ, Gromada J. Role of incretin hormones in the regulation of insulin secretion in diabetic and nondiabetic humans. Am J Physiol Endocrinol Metab 2004; 287: E199-E206.

4. Hare KJ, Vilsbøll T, Holst JJ, Knop FK. Inappropriate glucagon response after oral compared with isoglycemic intravenous glucose administration in patients with type 1 diabetes. Am J Physiol Endocrinol Metab 2010; 298: E832-E837.

5. Nauck M, Stöckmann F, Ebert R, Creutzfeldt W. Reduced incretin effect in type 2(non-insulindependent) diabetes. Diabetologia 1986; 29: 46-52.

6. Knop FK, Vilsbøll T, Højberg PV. Reduced incretin effect in type 2 diabetes: cause or consequence of the diabetic state? Diabetes 2007; 56: 1951-59.

7. $\mathrm{Wu} \mathrm{T}$, Rayner $\mathrm{CK}$, Jones $\mathrm{K}$, Horowitz $\mathrm{M}$. Dietary effects on incretin hormone secretion. Vitam Horm 2010; 84: 81-110. DOI: 10.1016/b978-0-12-381517-0.00003-5.

8. Cho YM, Kieffer TJ. K-cells and glucosedependent insulinotropic polypeptide in health and disease. Vitam Horm 2010; 84: 111-50.

9. Yavropoulok MP, Yovos JG. Central regulation of glucose-dependent insulinotropic polypeptide secretion. Vitam Horm 2010; 84: 185-210.

10. Hellstorm PM. Glucagon live peptide-1: Gastrointestinal regulatory role in metabolism and motility. Vitam Horm 2010; 84: 319-29.

11. Toft-Nielsen MB, Damholt MB, Madsbad S. Determinants of the impaired secretion of glucagon-like peptide-1 in type 2 diabetic patients. J Clin Endocrinol Metab 2001; 86: 3717-23.
12. Kreymann B, Williams G, Ghatei MA, Bloom SR. Glucagon-like peptide-1 a physiological incretin in man. Lancet 1987; 2: 1300-304.

13. Vollmer K, Holst JJ, Baller B. Predictors of incretin concentrations in subjects with normal, impaired, and diabetic glucose tolerance. Diabetes 2008; 57: 678-87.

14. Ryskjaer J, Deacon CF, Carr RD. Plasma dipeptidyl peptidase-IV activity in patients with type- 2 diabetes mellitus correlates positively with $\mathrm{HbA}_{1 \mathrm{c}}$ levels but is not acutely affected by food intake. Eur J Endocrinol 2006; 155: 485-93.

15. Afrin S, Sarkar CR, Zahid ATMZR, Ahmed N. Thyroid function in type 2 diabetes mellitus. J Bangladesh Soc Physiol 2017; 12(2): 61-64.

16. Kadiyala R, Peter R, Okosieme OE. Thyroid dysfunction in patients with diabetes: clinical implications and screening strategies. Int J Clin Pract 2010; 64(8): 1130-39.

17. Wolide AD, Zawdie B, Alemayehu T, Tadesse S. Association between thyroid hormone parameters and dyslipidemia among type 2 diabetes mellitus patients: Comparative cross-sectional study. Diabet Metab Syndr 2017; 11(SuppI 1): S257S262.

18. Singh P, Khan S, Mittal PK. Evaluation of thyroid dysfunction among type-2 diabetic mid and far western Nepalese population. J Coast Life Med 2014; 2(11): 903-6.

19. Kumar RA, Narasimhasetty KR, Lalitha R, Shetty SB. Prevalence of thyroid dysfunction among type 2 diabetes subjects in south India. J Clic Invest 2014; 5: 93-100.

20. Rahman M, Rahim A, Nahar Q. Prevalence and risk factors of type 2 diabetes in an urbanizing rural community of Bangladesh. Bangladesh Med Res Counc Bull 2007; 33: 48-54.

21. Holly JM, Amiel SA, Sandhu RR, Rees LH, Wass JA. The role of growth hormone in diabetes mellitus. J Endocrinol 1988; 118(3): 353-64.

22. Ahn CW, Kim CS, Nam JH, Kim HJ, Nam JS, Park JS, et al. Effects of growth hormone on insulin resistance and atherosclerotic risk 
factors in obese type 2 diabetic patients with poor glycemic control. Clin Endocrinol (Oxf) 2006; 64(4): 444-49.

23. Joseph N. Growth hormone deficiency and type 2 diabetes risk. Eur J Endocrinol 2012 Dec; www. Endocrineweb.com/author/ 20815/ editorialboard (Accessed on 21.03.2018).

24. Jhuma KA, Giasuddin ASM, Haq AMM, Huque MH. Incretin Hormones and Insulin Responses During OGTT in Newly Diagnosed T2DM Patients. Bangladesh Med Res Counc Bull 2017; 43(1): 31-36.

25. Holst JJ, Knop FK, Vilsboll T. Loss of incretin effect is a specific important and early characteristic of type diabetes. Diabetes Care 2011; 34(Suppl. 2): S251-S257.

26. Meier JJ, Nauck MA. Is the diminished incretin effect in type 2 diabetes just an epiphenomenon of impaired beta-cell function? Diabetes 2010; 59: 1117-25.

27. Nauck MA, El-Ouaghlidi A, Gabrys B. Secretion of incretin hormones (GIP and GLP-1) and incretin effect after oral glucose in first-degree relatives of patients with type 2 diabetes. Regul Pept 2004; 122: 209-17.
28. Hansen KB, Vilsboll T, Bagger JI. Reduced glucose tolerance and insulin resistance induced by steroid treatment, relative physical inactivity, and high-calorie diet impairs the incretin effect in healthy subjects. J Clin Endocrinol Metab 2010; 95: 3309-17.

29. Westwell-Roper C, Dai DL, Soukhatcheva Gl. IL-1 blockade attenuates islet amyloid polypeptide-induced proinflammatory cytokine release and pancreatic islet graft dysfunction. $\mathbf{J}$ Immunol 2011; 187(5): 2755-65.

30. Krogh-Madsen R, Plomgaard P, Moller K. Influence of TNF- $\alpha$ and IL-6 infusions on insulin sensitivity and expression of IL-18 in humans. Am J Physiol Endocrinol Metab 2006; 291: E108-E114.

31. Salliman CC, Kelher MR, Gamboni-Robetson F. Tumor necrosis factor- $\alpha$ causes release of cytosolic interleukin-18 from human neutrophils. Am J Physiol Cell Physiol 2010; 298(3): C714 - C724.

32. Souzal KLA, Gurgul-Convey E, Elsner M, Lenzen $\mathrm{S}$. Interaction between pro-inflammatory and antiinflammatory cytokines in insulin producing cells. J Endocrinol 2008; 197: 139-50. 